\title{
Theories used by nurses to promote patient safety practices: A scoping review
}

\author{
Ítalo L.S. Almeida*, Natana M. Ramos, Ítalo R.C. Andrade, Rhanna E.F.L. Carvalho, Lúcia F. Silva, Shérida K.P. \\ Oliveira, Sawori J.S.B. Anjos \\ Post-graduate Program Clinical Care in Nursing and Health, State University of Ceara, Fortaleza, Brazil
}

Received: November 25, 2021

Accepted: January 25, 2022

Online Published: February 25, 2022

DOI: $10.5430 /$ jnep.v12n7p1

URL: https://doi.org/10.5430/jnep.v12n7p1

\begin{abstract}
Aim: To review available scientific evidence in the literature on theories that have been used to promote patient safety practices in the hospital environment.

Methods: Design: A scoping review was conducted using the Preferred Reporting Items for Systematic reviews and MetaAnalyses extension for Scoping Reviews checklist. Method: the study was conducted between October and November 2020. The following databases were used to identify studies: Medline, Lilacs, BDENF, CINAHL, and Scielo Library. The following search key terms were used: "Patient Safety" AND "Nursing Theory" OR "Nursing Theories". Thirty-two studies were selected and analyzed, composing the review corpus. The studies were read and critically analyzed, followed by the discussion and interpretation of the results with the presentation of the identified evidence. The analysis was carried out using a descriptive method.

Results: The 32 articles that made up the study sample were published between 2006 and 2020 in 14 different countries and indicated the use of 34 different theories.

Conclusions: By analyzing the study sample, it was possible to identify nursing theories and theories in other fields of science. Some theories have been applied in the foundation of safe nursing care in different contexts and situations or the analysis and creation of safety culture protocols for healthcare organizations.
\end{abstract}

Key Words: Patient safety, Nursing, Theories, Evidence-based practices

\section{INTRODUCTION}

Theories support an understanding of how certain events occur. Therefore, they have a strong influence and applicability in professional practice. It is possible to identify situations that can promote excellence in nursing care. However, it is necessary that nurses increasingly improve their practices looking for safe care alternatives. The theoretical basis for improving care practices is also the purpose of theories.

Nurses should be encouraged to use theoretical perspectives to understand what information is important, how theories, The knowledge of theories, including those of nursing, can

\footnotetext{
*Correspondence: Ítalo L.S. Almeida; Email: italolennon@hotmail.com; Address: Avenue Dr. Silas Munguba, 1700 - Itaperi, Fortaleza, Ceara, Brazil.

Published by Sciedu Press 
lead to reflection and construction of scientific evidence in the conduct of nurses. Furthermore, there is potential for application in patient safety practices to improve the quality of care.

The issue of patient safety has been widely discussed worldwide, mainly due to the high incidence of adverse events related to the provision of health care, being recognized as an important indicator of quality. ${ }^{[4]}$ The World Health Organization (WHO), in a document published in 2010, has defined patient safety as reducing the risk of adverse events associated with health care at a minimum acceptable level. Adverse events are unintentional injuries caused by medical management rather than the underlying disease, leading to measurable injuries, death, or prolonged hospitalization. ${ }^{[5]}$

The nursing class councils have included the discussion agenda and indicated that the human factors contributing to errors are institutional, environmental, or related to lack of knowledge/skills regarding psychological and physiological responses. The situations that affect the quality of nursing practice and patient safety are job satisfaction, the number of professionals according to the type of category, teamwork issues, excessive working hours, occupational injuries, and violence against professionals. ${ }^{[6]}$

From this perspective, hospital institutions are increasingly concerned with ensuring safe care, offering excellent care, reducing costs, and ensuring customer satisfaction. ${ }^{[7,8]} \mathrm{A}$ study carried out in the south of Minas Gerais showed that the nurse's praxis in patient safety in the hospital environment is consolidated through leadership, the exercise of nursing management, and care based on communication with a focus on empathy, dialogue and in valuing strategies for continuing and permanent education. ${ }^{[8]}$

Therefore, hospitals have incorporated the aim of instituting safety as a cultural process, promoting greater awareness of professionals regarding the culture of safety and an ethical commitment in risk management, with the consequent acquisition of safety for themselves and the clients, overcoming the existing gap in the aspect of patient safety. ${ }^{[7]}$

Patient safety is an ethical issue in nursing care. It can be associated with reflections from nursing theories and theories in other fields since the dynamics of systematized and interrelated actions that professional nurses apply in their practice helps to implement patient-centered nursing care. Nursing has only managed to consolidate itself as a science and art because it has produced a specific language that gives meaning to the fundamental elements of the profession. Thus, it is possible to understand the representations of thought and the world, a communication vehicle or an instrument of action/interaction. ${ }^{[9]}$

The specific language is represented by nursing theories that aim to define, characterize, and explain/understand/interpret the phenomena that constitute the profession's domain of interest from the selection and conceptual interrelationship. Studies show that through previous learning experiences, theories organize ideas, describe events, people, or objects in which sets of knowledge are interrelated, thus forming a vision of nursing in its scope and practice. ${ }^{[9]}$

\section{BACKGROUND}

Nursing theories and those from other fields, used in nurses' practices, help understand reality, favor reflection and criticism, and serve as a basis for scientific elements in understanding and analyzing reality. The patient safety proposal seeks improvements to prevent errors and promote a culture of safety that involves professional nurses and the organization of the hospital structure broadly and comprehensively.

The correlation of nursing theories and other areas with patient safety in care practice raised questions that encouraged researchers to investigate what scientific evidence exists in the literature. This articulation of themes presented aims to investigate positive results and theoretical-philosophical conceptions that can offer safe nursing care to patients, families, and the community.

\section{Research question}

Given the above, the following question was proposed: Which theories have been used by nurses to promote patient safety practices in hospital settings?

\section{Methods}

This is a scoping review study. This method allows examining the extent and nature of scientific production or clarifying concepts that underlie a given area, identifying the feasibility or relevance of systematic reviews and, in this case, it works as a step prior to the systematic review that analyzes the review question, systematize and disseminate findings contributing to practice, policymaking, and research, identify gaps in the literature, and to reveal how studies from a given field of knowledge have been designed. ${ }^{[10,11]}$

The study was conducted between October and November 2020, using the Preferred Reporting Items for Systematic reviews and Meta-Analyses extension for Scoping Reviews (PRISMA-ScR) checklist, a guide for the reporting of scoping reviews. ${ }^{[12]}$ The PRISMA-ScR consists of 22 items divided into chapters: Title, Abstract, Introduction, Methods, Results, Discussion, and Funding. Information about the development of the review, the adjustments made, and the 
knowledge prior to the review should be described. Since this scoping review is not associated with a systematic review, it was not necessary to formally register the review protocol.

The review was guided by the following guiding question: Which theories have been used by nurses to promote patient safety practices in hospital settings? The Population, Concept, and Context (PCC) mnemonic method was used to determine the research question, as follows: Population: Nurses, Concept: Use of theories to promote patient safety practices, and Context: Hospitals.

Studies that addressed the use of nursing theories or theories from other fields used by nurses to promote patient safety practices in hospital institutions were included. No language or time restrictions were applied. Reviews, theoretical essays, theses, dissertations, and monographs were excluded, in addition to studies that did not align with the review's thematic design.

The following bibliographic databases were searched: Med- line (Medical Literature Analysis and Retrieval System Online), Lilacs (Latin American and Caribbean Health Sciences Literature), BDENF (Brazilian Nursing Database), and CINAHL (Cumulative Index to Nursing and Allied Health Literature). The Scielo Library (Scientific Electronic Library Online) was also consulted. The search terms were selected in MeSH using the mnemonic mentioned above. The following MeSH terms were used: "Patient Safety", "Nursing Theory", and its synonym "Nursing Theories". The Boolean operators AND and OR were added to compose the search key used in the databases, the second being applied between the synonymous terms. Finally, the search key "Patient Safety" AND "Nursing Theory" OR "Nursing Theories" was used.

Two reviewers independently searched and selected articles included in the sample to validate the search and selection processes. The flowchart depicted in Figure 1 shows the path for selecting the studies.

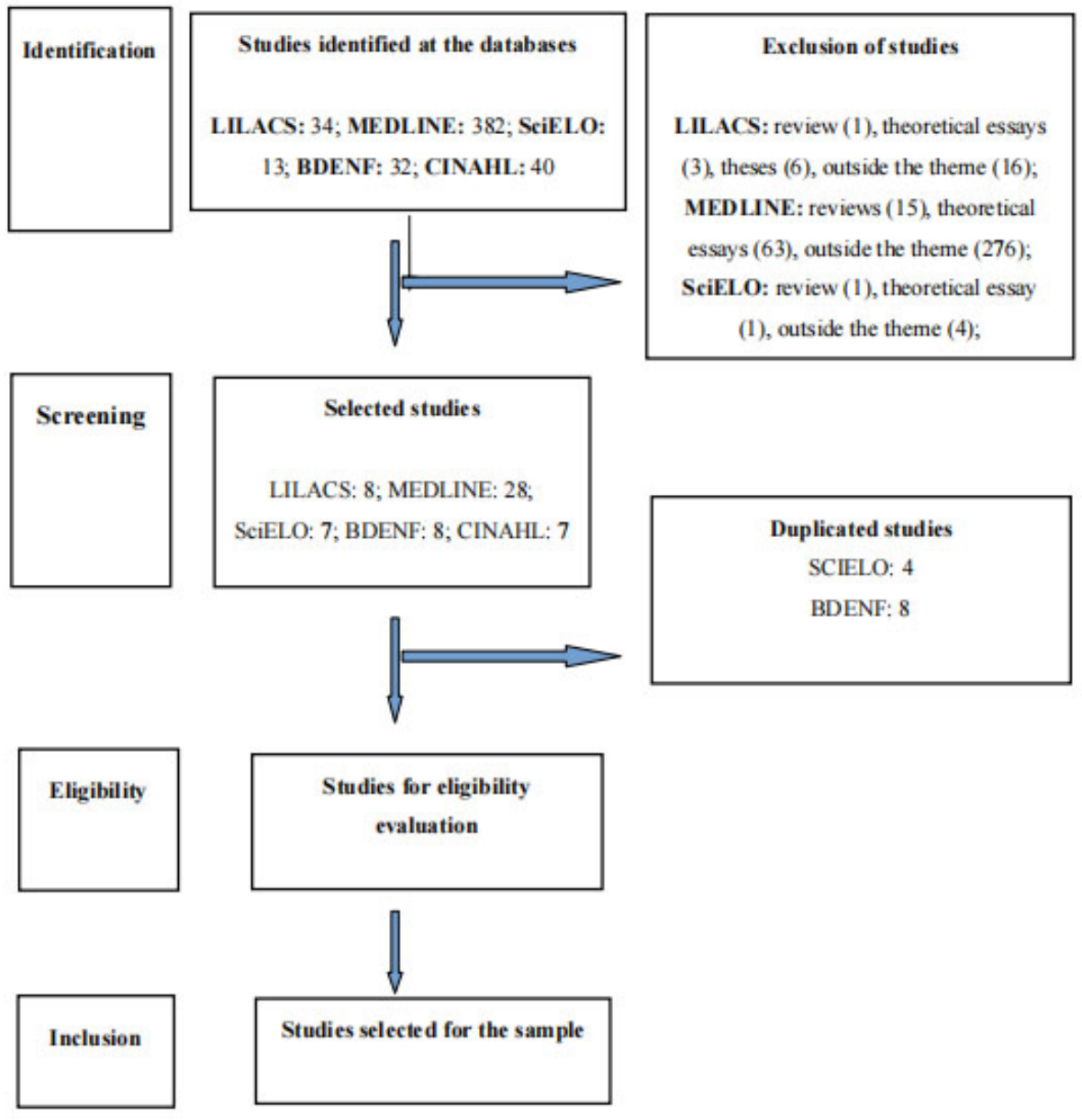

Figure 1. Study selection flowchart 
Eligible full-text articles were read by the two reviewers, which extracted the data previously defined using an instrument created by the researchers. The following information was extracted from each article: year of publication, country of origin, study objectives, methods, and theory used. Each reviewer arrived at a list of primary studies, and the two lists were compared and consolidated into one. Disagreements between the reviewers were solved through a discussion with a third reviewer. Thirty-two studies were selected and analyzed, composing the review corpus. The studies were read and critically analyzed. Then, the discussion and interpretation of the results were made, followed by the presentation of evidence. The analysis was carried out using a descriptive method. When it was impossible to determine the study design clearly, the nomenclatures used by the authors were adopted.

\section{Results}

The final sample consisted of 32 articles developed between 2006 and 2020, eight (25\%) published in Brazil, eight (25\%) in the United States, two (6.5\%) in Australia, Iran, Colombia, and Mexico, and one (3\%) in Canada, England, United Kingdom, Norway, Portugal, Belgium, Taiwan, and the Republic of Korea, respectively.

We identified 34 theories in the studies, of which nine (26\%) corresponded to the Corbin and Strauss' Grounded Theory, four (11\%) James Reason's Human Error Theory, two (6\%) Habermas' Theory of Communicative Action, Orem's SelfCare Deficit Theory, and Theory of Inventive Problem Solving, and one (3\%) of each of the following: Kolb's Theory of Experiential Learning, Theory of Sociology of Work, Watzlawick's Theory of Human Communication, Social Cognitive Theory, Westrum's Organizational Safety Culture Theory, Institutional Theory, General Theories of Safety, Normalization Process Theory, Grounded Constructivist Theory, Structural Contingency Theory, Roger's Diffusion of Innovations Theory, Grounded Theory, Reason's theory of "vulnerable system syndrome", Amalberti's theory of "migration to the boundaries", and the Work Process Theory. Table 1 summarizes the characteristics of the reviewed articles.

\section{Discussion}

\subsection{Patient safety practice grounded in theories: possi- bilities for nursing}

Nursing care in health institutions is developed with a focus on systematization. This aspect is a fundamental factor for the consolidation of modern nursing as a profession that bases its actions on scientific evidence, applies a consistent work method (under the strong influence of the scientific method), and analyzes its results in a critical-reflective man- ner.

In order to achieve systematic nursing work, the nursing process must be guided by evidence, organized actions, and meaningful results. It is, therefore, opportune to use theories. Using research and developing theory-based working methods to explain the implementation and integration of multifaceted interventions underpins the development of strategies to incorporate their use into practice. ${ }^{[13]}$

The proposal for changes or innovative approaches in nursing services based on the use of theories includes, according to the literature, interventions related to the communication between healthcare professionals, guidance for safe care for people with a tendency to self-injury, protocols for safe care in the operating room, improving student skills for safe and harm-free care, error analysis strategies and interventions for safe care in the intensive care unit, improving the understanding of patient safety protocols, and supporting theory in the development of clinical records for nurses. ${ }^{[13-23]}$

On the other hand, the use of theories seems to underpin the analysis of organizations' safety culture and serve as a theoretical framework for developing institutional practices and programs focused on forming an organizational safety culture or strengthening safe practices. The authors of the analyzed studies have different options as to how to carry out such analyzes through the use of articles about nursing errors, adverse events notifications, or by analyzing the discourse of nursing professionals and obtaining their perceptions, a theoretical framework for substantiating interventions with a focus on patient safety culture. ${ }^{[8,24-33]}$

The possibility of promoting safe practices with a focus on risk-controlled healthcare has become pertinent, with the use of theories that help systematize nursing actions and create work processes with a strong theoretical foundation. The studies analyzed demonstrated that the process of changing practices must involve many agents of transformation, including nurses in direct care positions, nursing managers, students, and researchers. It becomes evident that several dimensions of doing and being a professional need further development. Academia, health institutions, and entities that represent nursing must align with the paradigm shifts that affect the profession.

The analysis of the included studies allowed us to understand that the choice of theories to support patient safety practices or changes towards an organizational safety culture now opted for the adoption of theories created, substantiated, and validated by nursing researchers. Theories named "nursing theories" have now been applied and have their genesis in different areas (sociology, mathematics, and psy- 
chology) placed at the service of nursing researchers for an interdisciplinary contribution.

Thus, it was necessary to analyze the contribution of these theories under two perspectives to differentiate how theorists from nurses and other disciplines influence patient safety practices.

\subsection{Nursing theories in the patient safety culture}

Nursing theories provide the essence of decision-making about patient care with different approaches, whether in environment development, relationships, or a philosophical perspective, reducing the distance between theoretical models and practice.

Given this reality and the need to value nursing theories, everyday practices are, nowadays, not just a set of tasks, but promoting and qualifying the health status of patients and groups, as the theoretical assumptions underlie nursing as a science.

As a shared theory used by nurses, Social Cognitive Theory provides a framework for developing unique patterns. Nursing students who receive education and intervention that increases confidence and proficiency tend to have an enhanced self-efficacy, which plays a considerable role in promoting action. This theory is congruent with the principles of simulation training, and the concept of self-efficacy has been the object of research in simulation, an active learning method that influences student behavior. ${ }^{[16]}$

Besides being a tool for the development of health care, nursing theories offer structure and organization to nursing knowledge and give nurses a look at what is most important, leaving aside irrelevant data, thus facilitating the interpretation of data and the systematic planning of nursing interventions.

Researchers have developed a specific instrument to promote patient safety based on established international goals, given the lack of specific documents to document nursing surgical care in a Mexican hospital. Orem's Self-Care Deficit Theory was used as a theoretical foundation in the aforementioned study. ${ }^{[34]}$

Investigating the consonance between difficulties described by nurses and the exercise of professional practice is necessary to expose the complexity of the phenomena present in the field and factors that facilitate or compromise the quality of care. However, the context of care provision in health institutions has changed significantly in recent years, mainly due to technological advances. In addition, the nurse has become one of the main professionals engaged in risk management by spending more time in contact with the patient.
The nursing workforce must remain for longer periods with the patient given their care actions.

As a key player in risk management, the nurse promotes safe care. Therefore, the proposal to associate nursing theories with patient safety helps to qualify the actions of nursing professionals, providing systematized interventions capable of improving results and visibility of the nursing work.

With this perspective, it is necessary to carry out studies on nursing and patient safety theories, which can improve care, quality, and scientific knowledge of nursing as a science.

\subsection{Theories of other areas at the service of nursing in patient safety practices}

Nursing is challenged to grow and maintain its disciplinary bases worldwide, advancing in fulfilling its social commitment. Thus, although unique, the nursing discipline intersects with other disciplines, such as sociology, which justifies the use of references from other areas in the nurses' work. This is necessary because the nurse's work takes place in different spaces that make up the integrality of individuals. ${ }^{[22]}$

As a profession in the health area, nursing is characterized as a discipline that studies human care, and it materializes as a work performed in societies that evolve. Thus, nurses must know and appropriately use theories that support their practice, allowing them to perform sustained and systematized care. $^{[31,35]}$

The profession largely uses theories from other areas within its research, such as data-based theory (Grounded Theory), which originated in sociology and is adopted on a large scale today because it is based on field data collection and interventions, as highlighted in the literature. It was possible to identify that the theory has been used as a contribution to qualitative analysis in studies that explore the perceptions, understandings and interactions of nursing professionals with concepts that permeate patient safety and quality of care. Following the methodological proposal of Grounded Theory theorists, the studies included in this review have used the theory in the search for the construction of theoretical frameworks for the culture of patient safety. In an area that is still building its own knowledge, this becomes very important. ${ }^{[21,31]}$

Similarly, the Theory of Human Error, the second most cited in the reviewed studies, is largely used by nurses, especially in direct patient care. Its object of study is defined as any act that directly interferes with patient safety, with relevant impacts on nursing care. ${ }^{[14]}$ James Reason's theory has great prominence in patient safety studies, being recognized as the first to theoretically support much of the knowledge in the area that has been developed in the last two decades. Accord- 
ing to the findings of this review, it supports the analysis of human errors in different contexts (surgical center, intensive care unit) with a focus on systemic causes that may have conditioned such an occurrence, being applied inclusively in the analysis of ethical-disciplinary processes. ${ }^{[7,13,14,28]} \mathrm{Un}$ derstanding that people make mistakes for issues involving systemic failures is one of the main foundations that James Reason built with his theoretical approach. Therefore, it becomes ineffective to recognize specific errors and their consequences without carrying out in-depth analyzes of how working conditions have influenced their occurrence.

Theories from other areas focused on the culture of patient safety based on effective communication and practices involving managers, organizations, nursing professionals, and patients, supporting the planning of actions and the need to prevent errors and injuries. ${ }^{[26]}$

It is also worth noting the efforts to improve processes and enhance patient safety in public hospital settings through management strategies and institutional initiatives. ${ }^{[34]}$ Assistance actions have also been focused on in studies. The promotion of patient safety has been addressed through error identification strategies based on ethical-legal nursing principles $^{[8]}$ and the identification of causes associated with errors. ${ }^{[30]}$

In this sense, it would be important to adopt, from the academy, teaching strategies that enhance the appropriation of theoretical references, based on current realities and needs, inserting students in this universe and demonstrating its essentiality in the most varied contexts, with emphasis on the hospital ${ }^{[22,36]}$ for patient safety, a current trend and an essen- tial element for decreasing morbidity, mortality, and health care costs.

\section{Conclusion}

This scoping review identified studies in the literature that used theories to support nursing practice for patient safety. By analyzing the study sample, it was possible to identify nursing theories and theories from other fields of science.

The purpose of using such theories also showed two possible strands of analysis. Some of them are applied to the foundation of safe nursing care in different contexts and situations, such as surgical centers, intensive care units, delivery rooms, and the reorganization of work processes in general. However, the analyzed theories were also applied in the analysis and creation of safety culture protocols for health organizations. In this aspect, the theoretical foundation has been fundamental to systematize data regarding the health care practices of nurses and other professionals. Therefore, theories are useful to direct changes and highlight the paths for organizational transformations.

The synthesis of different studies made it possible to analyze the experiences of applying theories in nursing care practices and the repercussions of their use; therefore, future research and management actions may replicate the experiences presented here so that more organizations and professionals have their practices transformed to improve the quality of health care.

\section{CONFLicts OF InTEREST Disclosure}

The authors declare that there is no conflict of interest.

\section{REFERENCES}

[1] Parker ME, Smith MC. Nursing theory and the discipline of nursing. In Parker ME, Smith MC. Nursing theories and nursing practice. Davis FA; 2015. p. 3-18

[2] Kenney JW. Theory based advanced nursing pratice. In Cody WK. Philosophical and theoretical perspectives for advanced nursing practice. Jones \& Bartlett; 2013. p. 333-35.

[3] Risjord M. Nursing knowledge: science practice and philosophy Wiley-Blackwell; 2010.

[4] Bim LL, Bim FL, Silva AMB, et al. Theoretical-practical acquisition of topics relevant to patient safety: dilemmas in the training of nurses. Esc Anna Nery. 2017; 21(4): 1-6. https : //doi.org/10.1590/21 77-9465-ean-2017-0127

[5] World Health Organization. World Alliance for Patient Safety Forward Programme 2008-2009. WHO [cited 2021 out 12]; 2010. Available from: https://apps.who.int/iris/handle/10665/704 60

[6] Conselho Regional de Enfermagem do Estado de São Paulo. Seminário Paulista de Gestão SEPAGE. [cited 2021 out 12] 2011. Avail- able from: http://www.coren-sp.gov.br/sites/default/f iles/3_sepage_seguranca_paciente.pdf

[7] Claro CM, Krocokz DVC, Toffolleto MC, et al. Adverse events at the intensive care unit: nurses' perception about the culture of nopunishment. Rev. Esc. Enferm 201; 45(1): 167-72. PMid:21445504 https://doi.org/10.1590/S0080-62342011000100023

[8] Silva-Santos H, Santos TA, Alves AS, Silva MN, Costa HOG, Melo CMM. Error-producing conditions in nursing staff work. Revista Brasileira de Enfermagem 2018; 71(4): 1858-1864. PMid:30156670 https : //doi.org/10.1590/0034-7167-2017-0192

[9] Alcântara MR, Silva DG, Freiberger MF, Coelho MPPM. Teorias de enfermagem: a importância para a implementação da sistematização da assistência de enfermagem. Rev Cient Fac Educ e Meio Ambient. 2011; 2(2): 115-32. https ://doi .org/10.31072/rcf .v2i2. 99

[10] Joanna Briggs Institute. Joanna Briggs Institute Reviewers' Manual: 2015. The Joanna Briggs Institute; 2015.

[11] Schoeller SD, Lima DKS, Martins MM, Ramos FRS, Zuchetto MA, Bampi LNS, et al. Protocol for a scoping review on nursing care and the autonomy of disabled persons. BMJ Open. 2018; 8(10). 
PMid:30297347 https://doi.org/10.1136/bmjopen-2018-0 22106

[12] Tricco AC, Lillie R, Zarin W, et al. PRISMA Extension for Scoping Reviews (PRISMA-ScR): checklist and explanation. Annals of Internal Medicine. 2018; 169(7): 467-473. PMid:30178033 https://doi.org/10.7326/M18-0850

[13] Gillespie BM, Harbeck E, Lavin J, et al. Using normalisation process theory to evaluate the implementation of a complex intervention to embed the surgical safety checklist. BMC Health Services Research. 2018; 18(1): 170. PMid:29523148 https://doi.org/10.1186/ s12913-018-2973-5

[14] Duarte SCM, Bessa ATT, Buscher AMACS. Error characterization in intensive care nursing. Cogitare Enferm. [cited 2021 out 12] 2016; 21(5): 1-8. Available from: https://pesquisa.bvsalud.org/p ortal/resource/pt/biblio-1487

[15] Ribeiro GSR, Silva RC, Ferreira MA, Silva GR. Slips, lapses and mistakes in the use of equipment by nurses in an intensive care unit. Revista da Escola de Enfermagem da Usp. 2016; 50(3): 419-426. PMid:27556712 https ://doi .org/10.1590/S0080-6 23420160000400007

[16] Konicki T, Miller EU. Use of a simulation intervention to examine differences in nursing students' hand hygiene knowledge, beliefs, and behaviors. Nurse Education Today. 2016; 45: 96-101. PMid:27429413 https://doi.org/10.1016/j.nedt.2016.06 .022

[17] Taleghani YM, Rezaei F, Sheikhbardsiri H. Risk assessment of the emergency processes: healthcare failure mode and effect analysis. World Journal of Emergency Medicine 2016; 7(2): 97105. PMid:27313803 https://doi.org/10.5847/wjem.j. 192 $0-8642.2016 .02 .003$

[18] Carrera ALM, Torres DG, Arias GS, Bernardino E, Sousa SM. Nursing staff commmunication with the surgical team. Cogitare Enfermagem. 2017; 22(3). https://doi.org/10.5380/ce.v22i3.5 0928

[19] Lindley LC, Held ML, Henley KM, et al. Nursing Unit Environment Associated with Provision of Language Services in Pediatric Hospices. J Racial Ethn Health Disparities. 2016; 4(2): 252-258. PMid:27059050 https://doi.org/10.1007/s40615-016-022 4-1

[20] Arias-Botero JH, Padrón-Mercado CM. Portrayal of the performance of the post-anesthesia care unit, based on the perception of the profes. Colombian Journal of Anesthesiology. 2017; 45: 16-23. https://doi.org/10.1016/j.rcae.2017.09.008

[21] Soares RSA, Lima SBS, Eberhardt TD, et al. Incorporation of the pressure injury protocol in care management: grounded theory. Online Brazilian Journal of Nursing. 2017; 16(4): 389. https: //doi.org/10.17665/1676-4285.20175643

[22] Sun FK, Long A, Chiang CY, et al. A theory to guide nursing students caring for patients with suicidal tendencies on psychiatric clinical practicum. Nurse Education in Practice. 2019; 38: 157-163. PMid:31302590 https://doi.org/10.1016/j.nepr.2019.07 .001

[23] Uhm JY, Ko Y, Kim S. Implementation of an SBAR communication program based on experiential learning theory in a pediatric nursing practicum: a quasi-experimental study. Nurse Education Today. 2019; 80: 78-84. PMid:31280009 https://doi.org/10.1016/j.nedt .2019 .05 .034

[24] Espin S, Lingard L, Baker GR, et al. Persistence of unsafe practice in everyday work: an exploration of organizational and psy- chological factors constraining safety in the operating room. BMJ Quality \& Safety. 2016; 15(3): 165-170. PMid:16751464 https : //doi.org/10.1136/qshc.2005.017475

[25] Brixey JJ, Robinson DJ, Johnson CW, et al. Towards a hybrid method to categorize interruptions and activities in healthcare. International Journal of Medical Informatics. 2007; 76(11-12): 812-820. PMid:17110161 https://doi.org/10.1016/j.ijmedinf . 200 6.09 .018

[26] Dufault M, Duquette CE, Ehmann J, et al. Translating an EvidenceBased Protocol for Nurse-to-Nurse Shift Handoffs. Worldviews on Evidence-Based Nursing. 2010; 7(2): 59-75. PMid:20345512 https://doi.org/10.1111/j.1741-6787.2010.00189.x

[27] Jacobson CH, Zlatnik MMG, Kennedy HP, et al. Nurses' Perspectives on the Intersection of Safety and Informed Decision Making in Maternity Care. J Obstet Gynecol Neonatal Nurs. 2013; 42(5): 577-587. PMid:24003977 https ://doi .org/10.1111/1552-6909.1223 2

[28] Kongsvik T, Halvorsen K, Osmundsen T, et al. Strengthening patient safety in transitions of care: an emerging role for local medical centres in norway. BMC Health Services Research. 2016; 16(452) PMid:27576322 https://doi.org/10.1186/s12913-016-170 8-8

[29] Correia T, Martins M, Forte E. Processes developed by nurse managers regarding the error. Revista de Enfermagem Referência. 2017; 4(12): 75-84. https://doi.org/10.12707/riv16073

[30] Forte ECN, Pires DEP, Martins MMFPS, et al. Between error and success: promoting patient safety based on the reporting of adverse events. Revista Eletrônica de Enfermagem. 2018; 20. https : //doi.org/10.5216/ree.v20.52539

[31] Vinckx MA, Bossuyt I, Casterlé BD. Understanding the complexity of working under time pressure in oncology nursing: a grounded theory study. International Journal of Nursing Studies. 2018; 87: 60-68 PMid:30055374 https://doi.org/10.1016/j.ijnurstu. 201 8.07 .010

[32] Mossburg SE, Weaver S, Pillari MS, et al. Manifestations of HighReliability Principles on Hospital Units with Varying Safety Profiles. Journal of Nursing Care Quality. 2019; 34(3): 230-235. PMid:30480611 https://doi.org/10.1097/NCQ.0000000000 000368

[33] Koerich C, Erdmann AL, Lanzoni GMM. Professional interaction in management of the triad: permanent education in health, patient safety and quality. Revista Latino-Americana de Enfermagem. 2020; 28: 3379-3379. PMid:33027407 https://doi .org/10.1590/15 $18-8345.4154 .3379$

[34] Morales ES. Formato de registros clínicos de enfermería quirúrgica Enf Neurol. 2012; 11(1): 14-20. https://doi.org/10.37976/e nfermeria.v11i1.116

[35] Kneafsey R, Clifford C, Greenfield S. What is the nursing team involvement in maintaining and promoting the mobility of older adults in hospital? A grounded theory study. International Journal of Nursing Studies. 2013; 50(12): 1617-1629. PMid:23701959 https://doi.org/10.1016/j.ijnurstu.2013.04.007

[36] Norwood BR. The Integration of a Program of Structured Simulation Experiences in a SCDNT Based Curriculum. 10th IOS WORLD-Congress o SCDNT. [cited 2021 out 12] 2018. Available from: http://static1.squarespace.com/static/55f $1 \mathrm{~d} 47$ 4e4b03fe7646a4d5d/t/56cda852e707eba9b0af737a/14563 18556457/Abstractbook-10th-IOS-2008.pdf 